\title{
Analysis of the impact of the labyrinth seal geometric parameters on the leakage
}

\author{
Damian Joachimiak ${ }^{1 *}$ and Piotr Krzyślak ${ }^{2}$ \\ ${ }^{1}$ Poznan University of Technology, Ul. Piotrowo 3, 60-965 Poznań \\ ${ }^{2}$ Uniwersytet Morski w Gdyni, Ul. Morska 81-87, 81-226 Gdynia
}

\begin{abstract}
This paper includes results of experimental research and CFD calculations concerning gas flow in segments of straight through labyrinth seals of fixed length and varying number of teeth. Relation between the number of teeth and the leakage is analyzed in this paper. Authors determined the range of teeth number for which the minimum leakage was achieved. They focused particularly on the analysis of geometry with maximum number of teeth which fell within the range of the minimum leakage. For this geometry they examined the relation between the thickness of the teeth and the distribution of gas pressure and velocity along the seal and the leakage size. Data presented in this paper indicate that the teeth thickness has a significant impact on the flow parameters.
\end{abstract}

\section{Introduction}

Labyrinth seals are widely applied in fluid-flow machines. The most popular among them are straight through labyrinth seals [1]. They are installed in steam turbines in places being far from thrust bearings [2]. Seals of that type are also used to reduce leakage in piston-cylinder assemblies in combustion engines [3,4]. Labyrinth seals are applied in nuclear reactors to control the flow of a cooling medium [5]. Experimental tests and CFD calculations for straight through seals are described in reference papers [6-8]. Research work comprises the analysis of thermo-dynamic and flow phenomena occurring in seals of that type. The influence of the dimensions of clearance on the leakage value was analyzed in [9]. In papers [10,11] the optimal choice of the geometry of the straight through seal to minimize the leakage was investigated. The search for the optimal seal geometry is an inverse problem of the geometric type [12][13][14][15].

In this paper some considerations related to the impact of the tooth thickness on the leakage are presented.

\section{Scope of experimental research}

The test stand used for experimental research (fig. 1) consists of the compressor, the compressed air tank, the mass flow measurement system, the body of the model seal segment and of the measuring system. In the body (fig. 1., element 5) there is an insert (fig. 2, 3), on which the seal model is installed. Data concerning the seal geometry are presented in figure 2 and summarized in table 1. Experimental research focused on a segment of the straight through seal of the radial clearance $\mathrm{RC}$ of
$0.542 \mathrm{~mm}$. Fixed length of segment $\mathrm{LS}=31 \mathrm{~mm}$ and the tooth thickness $\mathrm{B}=1 \mathrm{~mm}$ (table 1) were assumed. Experimental research was conducted for the segment of 11 teeth.

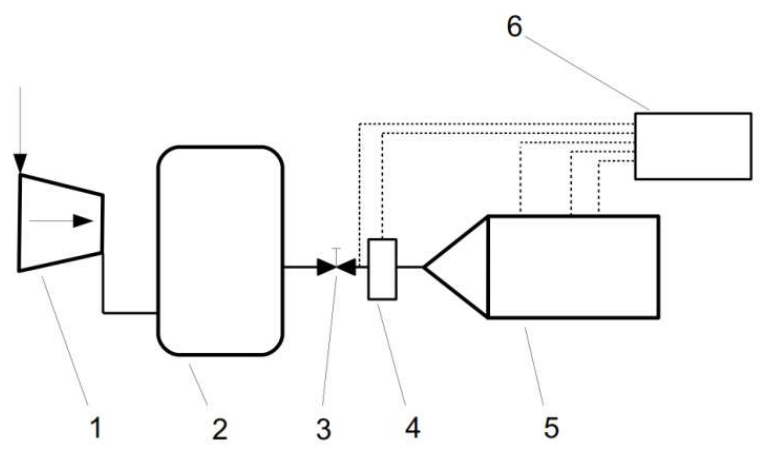

Fig. 1. Diagram of the measurement stand, 1 - compressor, 2 - main tank, 3 - control valve, 4 - measuring orifice in the inflow channel, 5 -body, 6 - measuring system

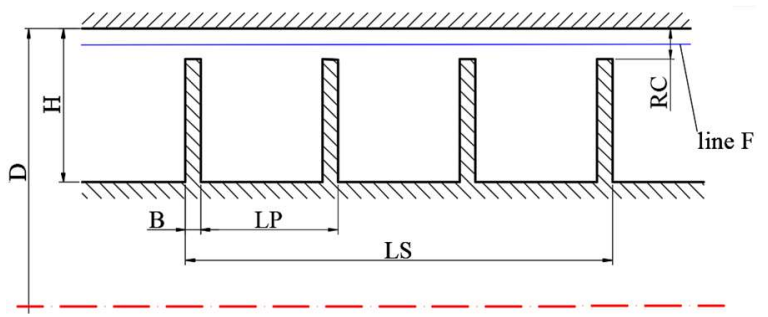

Fig. 2. Geometry of model seal segment.

\footnotetext{
* Corresponding author: damian.joachimiak@put.poznan.pl
} 
Table 3. Marking and dimensions of geometry.

\begin{tabular}{|c|c|c|}
\hline Symbol & Description & $\begin{array}{c}\text { Dimensions } \\
{[\mathrm{mm}]}\end{array}$ \\
\hline D & Seal diameter & 150 \\
\hline LS & Length of segment & 31 \\
\hline LP & Length of pitch & 3 \\
\hline H & Segment height & 10 \\
\hline RC & Radial clearance & $0.362 ; 0.542$ \\
\hline B & Tooth thickness & $\begin{array}{c}0.6 ; 0.8 ; 1 ; \\
1.2\end{array}$ \\
\hline
\end{tabular}

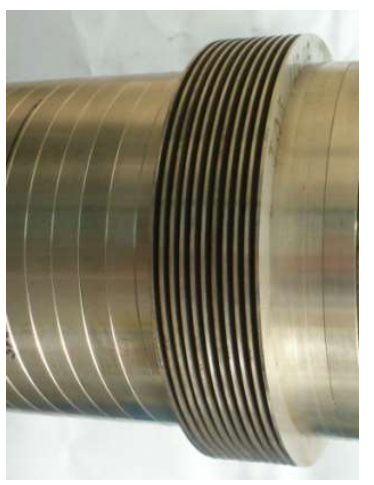

Fig. 3. Insert with eleven discs

\section{Scope of CFD research}

Numerical calculations were performed in the Fluent 13 software. Geometry (fig. 4) has an inflow and outflow segments of the length of $2 \mathrm{LS}$ and 3.5LS, respectively. The considerable length of the outflow segment results from the occurrence of gas swirl behind the last tooth of the segment. Data referring to the seal geometry summarized in table 1 were taken for CFD calculations; tooth thickens B of $0.6 ; 0.8 ; 1$ and $1.2 \mathrm{~mm}$ was analyzed.

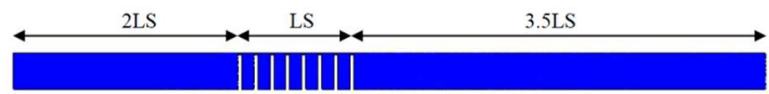

Fig. 4. Calculation domain.

The geometry under investigation is 2D-type axisymmetric geometry. For the chosen geometry, the grid consists of 357000 elements and 361000 nodes. In the boundary layers 20 grid cells were assumed. SST k$\omega$ turbulence model was used for calculations. To meet the requirements of the grid quality for the SST k- $\omega$ model, the condition $\mathrm{y}+<2$ was assumed in the boundary layer. Based on experimental data, in the inlet plane the total pressure was set, and in the outlet plane the static pressure was given. In CFD calculations temperature of gas, of the body and of the insert was given based on data obtained during experimental tests. This paper presents RANS-type 2D steady calculations. Mass, momentum and energy conservation equations were included. Calculations were performed for the air assumed as the ideal gas.

\section{Results of research}

Initial experiments were performed for seal segments composed of 4, 6, 9 and 11 teeth [10]. It was assumed that the reference geometry is s segment composed of four teeth. Next, the relative change of mass flow obtained from the experiments for other considered segments was determined

$$
\delta \dot{m}_{e, e-4 t}=\frac{\dot{m}_{e-4 t}-\dot{m}_{e}}{\dot{m}_{e-4 t}} \cdot 100 \%
$$

Similarly, the mass flow obtained with the use of the Fluent software was compared with the mass flow obtained from experiments for the segment of four teeth

$\delta \dot{m}_{F, e-4 t}=\frac{\dot{m}_{e-4 t}-\dot{m}_{F}}{\dot{m}_{e-4 t}} \cdot 100 \%$

Figure 5 presents the percentage change in the mass flow obtained from measurements and from the Fluent software. These results are compared with the mass flow obtained from the experiment for a 4-tooth segment.

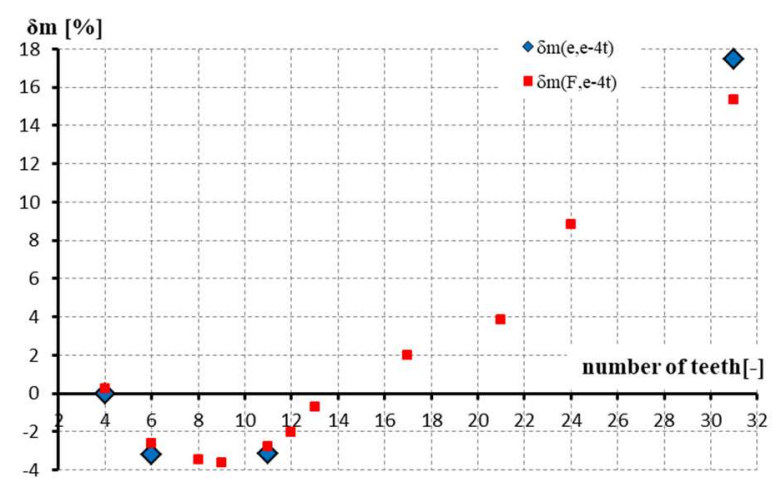

Fig. 5. Relative change of mass flow in segments under consideration obtained from the experiment $\mathbf{\square m}$ e,e-4t and from the Fluent software $\mathbf{a m F , e - 4 t}$ compared with the result obtained from the experiment for the comparative geometry of 4 teeth (e-4t) [10]

Minimal leakage obtained from the experimental research was achieved for the segment with the number of teeth ranging from 6 to 11. Further part of this paper is focused on the geometry with 11 teeth. It presents analysis of the impact of the tooth thickness on the leakage (fig. 5). This analysis was performed for the segment long of $31 \mathrm{~mm}$ and comprising 11 teeth of various thickness: $0.6,0.8,1,1.2 \mathrm{~mm}$. Thickness of teeth in the segment has a direct impact on the length (volume) of chambers. The thicker are teeth, the shortest are chambers, and the geometry of the labyrinth seal becomes similar to the slot seal. Figure 6 presents the distribution of gas velocity in the segment of 11 teeth being $0.6 \mathrm{~mm}$ thick. 


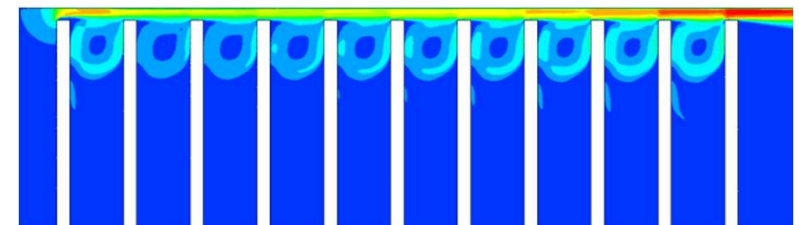

Fig. 6. Distribution of gas velocity in the seal of the radial clearance $\mathrm{RC}=0.542 \mathrm{~mm}$ and tooth thickness $\mathrm{B}=0.6 \mathrm{~mm}$

In the upper part of the geometry gas flows with a high velocity which is increasing gradually from the second clearance from 134 to $226 \mathrm{~m} / \mathrm{s}$. In the geometry having teeth thick of $0.6 \mathrm{~mm}$ considerable swirls of gas are observed only in the upper part of chambers. In the bottom part of chambers the gas velocity is close to zero. Figure 8 presents the distribution of the gas axial velocity in the segment of the radial clearance $\mathrm{RC}=0.362 \mathrm{~mm}$ read from the line $\mathrm{F}$ being in the middle part of the clearances. CFD simulations were performed for the pressure ratio $\mathrm{p}_{01} / \mathrm{p}_{2}=2$.

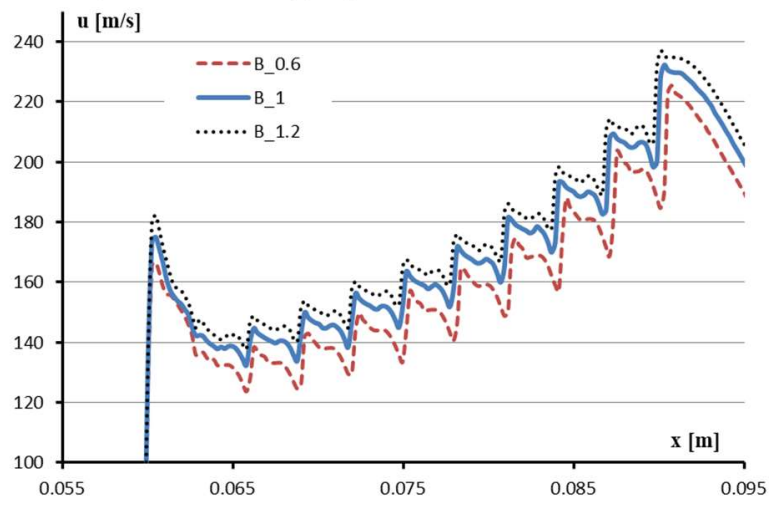

Fig. 7. Distribution of the gas velocity in the axial direction along the seal length read from the line F (fig. 2)

For the considered geometries, the greatest increase of gas velocity from approx. 3 to more than $160 \mathrm{~m} / \mathrm{s}$ occurs in the area of the first clearance. Maximum gas velocities in clearances are observed in the segment having the thickest teeth of $B=1.2 \mathrm{~mm}$. The effect of the increase of gas velocity in clearances is the most noticeable for the segment having teeth of the smallest thickness. Static pressure drop is the largest in the area of the first clearance (fig. 9). In subsequent clearances the largest drops of the static pressure are observed for the segment of the thinnest teeth.

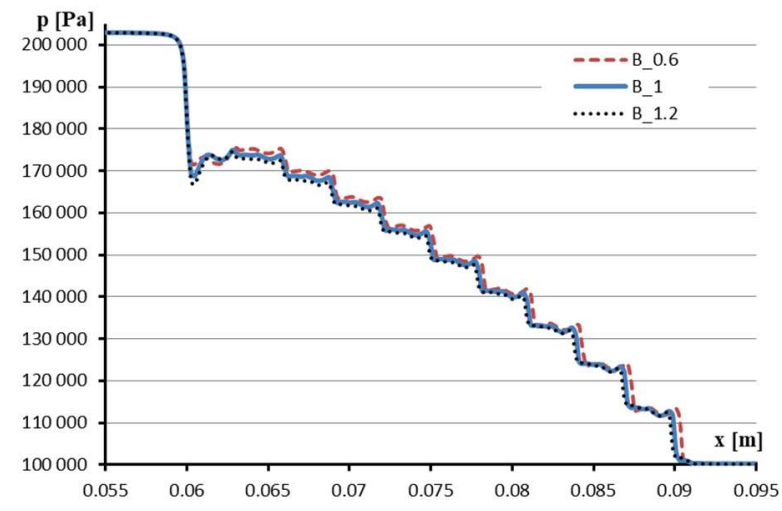

Fig. 8. Distribution of the static pressure along the seal length read from the line F (fig. 2)

In the initial part of the analyzed segments we can observe a non-uniform pressure drop in the area of clearances. It differs considerably from the theoretical assumptions [1]. Gas expands in clearances. In these spaces the static pressure decreases and the velocity increases. Gas kinetic energy dissipation proceeds in chambers of the seal. Based on numerical calculations made for the segment of 11 teeth it was proved that when the thickness of teeth grows from 0.6 to $1.2 \mathrm{~mm}$, the gas mass flow flowing through the segment also increases (fig. 9). The nature of changes in the mass flow for segments having clearances of height of 0.362 and 0.542 depending on the teeth thickness is similar.

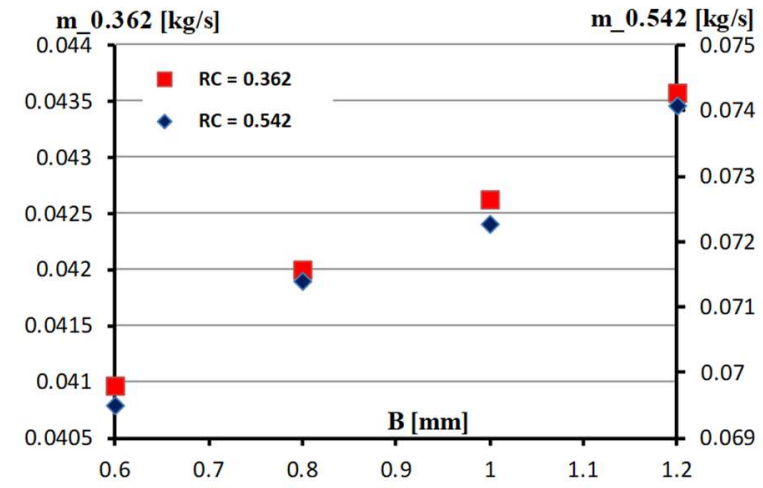

Fig. 9. Value of the mass flow in the segment of 11 teeth depending on teeth thickness for the segment of the radial clearance $\mathrm{RC}=0.362 \mathrm{~mm}$ and $\mathrm{RC}=0.542 \mathrm{~mm}$

For the segment of the radial clearance of 0.362 and $0.542 \mathrm{~mm}$ and the considered range of teeth (discs) thickness the change in the mass flow reaches the value of 0.0026 and $0.0045 \mathrm{~kg} / \mathrm{s}$, respectively. This value constitutes 6.1 and $6.3 \%$, respectively, of the relative change in mass flow compared with the segment having teeth thick of $B=1 \mathrm{~mm}$. In the segment of the thinnest teeth the best conditions for dissipation of gas kinetic energy exist which results in achieving the smallest leakage. The greater is the teeth thickness, the larger seal leakage is observed (fig. 9). Gas expansion in clearances is fading and the nature of the flow becomes similar to the flow occurring in the slot seal [11].

\section{Conclusion}

Change of the number of teeth in the straight through labyrinth seal of a given length impacts on the leakage. For the set pressure drop there is a range of optimal number of teeth for which the leakage is minimal. The number of teeth impacts on the size of seal chambers, and particularly, on their length. It influences on the conditions of the gas kinetic energy dissipation. Results of research presented in this paper indicate that the increase of tooth thickness from 0.6 to $1.2 \mathrm{~mm}$ results in the increase of leakage. Therefore, we should try to minimize the teeth thickness. Limitation of the thickness reduction is the tooth strength resulting from the operation conditions and the pressure drop on one tooth. Tooth thickness should be chosen in such a way to avoid tooth damage being the result of the acting pressure. 


\section{Nomenclature}

D - seal diameter, $\mathrm{m}$

c - specific heat, $\mathrm{J} / \mathrm{kgK}$

$L S \quad$ - length of segment, $\mathrm{m}$

$L P \quad$ - length of pitch, $\mathrm{m}$

$H \quad$ - segment height, $\mathrm{m}$

$R C$ - radial clearance, $\mathrm{m}$

$B \quad$ - tooth thickness, $\mathrm{m}$

$\dot{m}$ - mass flow, $\mathrm{kg} / \mathrm{s}$

\section{References}

1. K. Trütnovsky, Berührungsfreie Dichtungen,

Grundlagen Und Anwendungen Der Strömung Durch Spalte Und Labyrinthe (VDI-Verlag bh Düsseldorf, Verlag des Vereins Deutscher Ingenieure, 1964)

2. W. Traupel, Termische Turbomaschinen, Ester B. (Springer, Berlin, 2001)

3. J. Larjola, J. Honkatukia, P. Sallinen, and J. Backman, J. Therm. Sci. 19, 141 (2010)

4. J. Feng, L. Wang, H. Yang, and X. Peng, Math. Probl. Eng. 2018, 1 (2018)

5. H. Qin, D. Lu, D. Zhong, Y. Wang, and Y. Song, Ann. Nucl. Energy 135, 106964 (2020)

6. D. Joachimmiak, J. Appl. Fluid Mech. 13, 935 (2020)

7. D. Joachimiak and P. Krzyślak, Polish Marit. Res. 24, 83 (2017)

8. D. Joachimiak and P. Krzyślak, Arch. Thermodyn. 36, 61 (2015)

9. D. Joachimiak and A. Frąckowiak, Energies 13, 5794 (2020)

10. W. Wróblewski, D. Frączek, and K. Marugi, Int. J. Heat Mass Transf. 126, 725 (2018)

11. D. Joachimiak and P. Krzyśłak, J. Appl. Fluid Mech. 12, 921 (2019)

12. S. P. Asok, K. Sankaranarayanasamy, T. Sundararajan, K. Rajesh, and G. Sankar Ganeshan, Tribol. Int. 40, 1204 (2007)

13. A. Frackowiak, A. Olejnik, A. Wróblewska, and M. Ciałkowski, Energies 14, (2021)

14. M. Joachimiak, Energies 14, (2021)

15. M. Joachimiak, Int. J. Numer. Methods Heat Fluid Flow 30, (2020)

16. D. Joachimiak and P. Krzyślak, Arch. Thermodyn. 37, 95 (2016) 